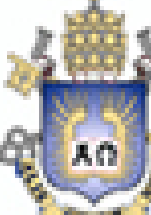

Leonardo Viana de Freitas

Síntese e caracterização de compostos formados entre a cisplatina e os ligantes

\author{
glutationa ou penicilamina
}

Dissertação de Mestrado

Dissertação apresentada ao Programa de Pós-Graduação em Química da PUC-Rio como requisito parcial para obtenção do título de Mestre em Química.

Orientadora: Prof. Judith Felcman

Rio de Janeiro

Fevereiro de 2010 
Leonardo Viana de Freitas

\section{Síntese e caracterização de compostos formados entre a cisplatina e os ligantes glutationa ou penicilamina}

Dissertação apresentada ao Programa de Pós-Graduação em Química da PUC-Rio como requisito parcial para obtenção do título de Mestre em Química. Aprovada pela Comissão Examinadora abaixo assinada.

Prof. Judith Felcman

Orientadora

Departamento de Química - PUC-Rio

Prof. Andréa de Moraes Silva

IFRJ

Prof. Marciela Scarpellini

UFRJ

Prof. Nicolás Adrián Rey

Departamento de Química - PUC-Rio

Prof. José Eugenio Leal

Coordenador Setorial de Pós-Graduação do

Centro Técnico Científico - PUC-Rio

Rio de Janeiro, 9 de fevereiro de 2010 
Todos os direitos reservados. É proibida a reprodução total ou parcial do trabalho sem autorização da universidade, do autor e do orientador.

\section{Leonardo Viana de Freitas}

Graduou-se em Licenciatura Química no Centro Federal de Educação Tecnológica de Química de Nilópolis (atual IFRJ) em fevereiro de 2008. Ingressou no Mestrado em Química na PUC-Rio em março do mesmo ano.

Ficha Catalográfica

$$
\text { Freitas, Leonardo Viana de }
$$

Síntese e caracterização de compostos formados entre a cisplatina e os ligantes glutationa ou penicilamina / Leonardo Viana de Freitas ; orientadora: Judith Felcman. 2010.

103 f. : il. (color) ; $30 \mathrm{~cm}$

Dissertação (Mestrado)-Pontifícia Universidade Católica do Rio de Janeiro, Departamento de Química, Rio de Janeiro, 2010.

Inclui bibliografia

1. Química - Teses. 2. Cisplatina. 3. Glutationa.

4. Penicilamina. 5. Complexos. I. Felcman, Judith. II. Pontifícia Universidade Católica do Rio de Janeiro. Departamento de Química. III. Título. 
À minha ex-professora de Química Inorgânica e amiga, Andréa de Moraes, por ter sido instrumento para o meu despertar para essa área da química e por todo profissionalismo e dedicação dispensados a mim. 


\section{Agradecimentos}

Ao Senhor Jesus, o meu Deus, pelo seu amor por mim, pela renovação de forças e por suas misericórdias, que não têm fim. Sem Ti, nada posso.

Aos meus pais e familiares que tanto me apoiam. Agradeço, em especial, a meus pais, Raimundo e Maria das Graças, à minha avó, Maria José, e a meus tios, Mário e Sonia.

À professora Judith Felcman pelo suporte em toda a pesquisa e em momentos difíceis que enfrentei.

À Aline, minha querida amiga. Sua companhia é algo privilegiado para mim. Por todo conhecimento partilhado comigo, por ser tão prestativa, por suas orações, pelo seu apoio. De fato, há amigos mais chegados que irmãos.

À Maria Stella, minha querida amiga. Por todos os belos momentos de conversas, troca de ideias, fortificação, compreensão. És grande companheira.

Aos meus amigos Rafaela, Vanessa, Pablo, Marcelo e Dayse pelo constante incentivo e interesse pelo meu bem estar.

À Luciana, por sua bondade, por sua alegria contagiante e pela sua disposição a ajudar.

À professora Andréa, pelo seu exemplo para mim. Continuo dizendo que você é minha inspiração sobre o que é ser um professor.

Ao professor Tiago, meu professor de Físico-Química na graduação, que agora, mesmo um pouco distante, sempre esteve aberto para bons momentos de conversa e incentivo. 
À professora Barbara, por toda ajuda prestada durante seu momento de convívio comigo no laboratório.

Às colegas de laboratório Luciene, Natalie e Thaís pela ajuda prestada em tantos momentos.

À Fátima, secretária da pós-graduação, por sua gentileza e atenção.

Ao Rodrigo, do laboratório de Absorção Atômica, por sua gentileza e disposição a ajudar.

Ao Maurício, do laboratório de ICPOES, pela realização da análise de platina e ao professor Norbert Miekeley, pela concessão da análise.

Ao Caio, Jorge, Thiago, Cristiane, Elaine e Débora, pertencentes à equipe técnica dos laboratórios da professora Judith, pelas suas análises e prestação.

Aos funcionários da biblioteca do CTC Guilherme, Bernadete e Sandra.

Aos professores que participaram da comissão examinadora.

À Quiral Química do Brasil pelo fornecimento da cisplatina.

À PUC-Rio, pela oportunidade e suporte para realizar esses estudos.

Ao CNPq e à FAPERJ pelo apoio financeiro, indispensável para minha manutenção e confecção da pesquisa. 


\section{Resumo}

Viana de Freitas, Leonardo; Felcman, Judith. Síntese e caracterização de compostos formados entre a cisplatina e a glutationa ou penicilamina. PUC-Rio, 2010. 103p. Dissertação de Mestrado - Departamento de Química, Pontifícia Universidade Católica do Rio de Janeiro.

A cisplatina é um dos mais importantes agentes quimioterápicos usados no tratamento de diversos tipos de câncer. Entretanto, seu uso ocasiona efeitos colaterais, como ototoxicidade, neurotoxicidade e, em especial, a nefrotoxicidade, que é um dos mais significativos. Isso tem sido relacionado à interação da cisplatina com biomoléculas sulfuradas, como proteínas e aminoácidos. De modo a reduzir esses efeitos, tem-se sugerido a co-administração de certos compostos químicos sulfurados, denominados agentes salvadores, junto à cisplatina, o que poderia impedir sua interação com as moléculas sulfuradas no organismo e, por sua vez, a redução dos efeitos colaterais. Dentre esses agentes, sugere-se o tripeptídeo glutationa e o aminoácido penicilamina. A glutationa é o principal agente desintoxicante e antioxidante do organismo, sendo indispensável à homeostase celular, e a penicilamina é utilizada como medicamento no tratamento da doença de Wilson e artrite reumatoide. Dessa forma, visou-se, com este trabalho, a síntese e caracterização de dois complexos entre a cisplatina e os mesmos. A partir das técnicas de caracterização, que foram análise elementar, análise termogravimétrica e espectroscopias no infravermelho e Raman, foi possível sugerir uma estrutura para cada um dos complexos em que os ligantes se comportam de forma monodentada, sendo o enxofre o átomo doador. Isso ratificou o que é predito pelo conceito de ácidos e bases duros e macios, que comenta que ácidos de Lewis macios, que é o caso de $\mathrm{Pt}^{2+}$ presente na cisplatina, têm grande afinidade química por bases de Lewis macias, que é o caso do enxofre presente no grupo tiolato dos ligantes desprotonados. O uso de cálculos teóricos, baseados nas estruturas propostas, como uma técnica recurso complementar de caracterização, foi de grande utilidade, já que, através dos mesmos, foi possível atribuir com maior segurança certas bandas presentes nos espectros de infravermelho e Raman experimentais.

\section{Palavras-chave}

Cisplatina; glutationa; penicilamina; complexos. 


\section{Abstract}

Viana de Freitas, Leonardo; Felcman, Judith (Advisor). Synthesis and characterization of compounds formed between cisplatinum and glutathione or penicillamine ligands. PUC-Rio, 2010. 103p. MSc. Dissertation - Departamento de Química, Pontifícia Universidade Católica do Rio de Janeiro.

Cisplatinum is considered an important chemotherapeutic drug used against some kinds of cancer. However, the use of this drug may cause side effects such as ototoxicity, neurotoxicity and, mainly, nephrotoxicity. This fact has been related to the interaction of cisplatinum with biomolecules containing sulfur, such as proteins and amino acids. To promote the reduction of these effects, the coadministration of some compounds, called rescue agents, has been suggested in an attempt to prevent the interaction between cisplatinum and those biomolecules. Glutathione, a tripeptide, and the amino acid penicillamine could be used for this purpose. The former is the most important antioxidant in the human body and acts in cell homeostasis, and the latter is used in the treatment of Wilson's disease and rheumatoid arthritis. Thus, considering the possibilities of interaction between cisplatinum and these sulfur agents, this work intended to synthesize and characterize the compounds formed by them. Using characterization techniques such as elementary analysis, thermogravimetry, and infrared and Raman spectroscopies, it was possible to suggest the structure of each compound, in which the ligands behaved as monodentate, bounding through the sulfur atom. This agree with the theory of soft and hard acids and bases, which predicts the affinity between platinum (Lewis acid) and sulfur (Lewis base). The use of theoretical calculations based on the structures proposed was very useful because it was possible to attribute some bands in the infrared and Raman spectra with more certainty.

\section{Keywords}

Cisplatinum; glutathione; penicillamine; complexes. 


\section{Sumário}

1 Introdução

2 Cisplatina 21

2.1. Aspectos Gerais $\quad 21$

2.2. Histórico 21

2.3. Mecanismo de Ação 23

2.3.1. Captação celular e hidrólise da cisplatina 23

2.3.2. Interação da cisplatina com o DNA 24

2.3.3. Ação Antitumoral 24

2.3.4. Toxicidade 26

3 Ligantes $\quad 28$

3.1. Penicilamina 28

3.1.1. Aplicações 29

3.1.2. Toxicidade 30

3.2 Glutationa 31

3.2.1. Aplicações 32

3.2.2. Interação entre glutationa e cisplatina 35

4 Experimental $\quad 37$

4.1. Reagentes 37

4.2. Equipamentos $\quad 37$

4.3.1. Análise Elementar 38

4.3.2. Análise Termogravimétrica 38

4.3.3. Espectroscopia de Infravermelho (IV) 39

4.3.4. Espectroscopia Raman 39

4.3.5. Ensaio qualitativo para a determinação de cloreto 39

4.3.6. Síntese dos compostos 40 
5 Resultados e discussão 41

5.1. Análise Elementar 41

5.2. Faixa de decomposição 42

5.3. Análise Termogravimétrica 43

5.4. Ensaio analítico qualitativo para testar a presença de cloreto 44

5.5. Infravermelho e Raman 44

5.6. Propostas de Estrutura $\quad 45$

5.7. Determinação estrutural e parâmetros geométricos 46

5.7.1. Atribuições vibracionais 51

5.7.1.1. Estiramentos $\mathrm{OH}$

5.7.1.2. Estiramentos $\mathrm{NH}$

5.7.1.3. Estiramentos $\mathrm{CH}$

5.7.1.4. Estiramentos $\mathrm{C}=\mathrm{O} \quad 56$

5.7.1.5. Deformações $\mathrm{NH}_{3}$ e $\mathrm{NH}_{3}{ }^{+} \quad 56$

5.7.1.6. Amida I e amida II 57

5.7.1.7. Deformações $\mathrm{CH}_{3}$

5.7.1.8. Variações angulares $\mathrm{HCH}$

5.7.1.9. Estiramentos PtN, PtS e PtCl 58

5.7.1.10. Principais atribuições para os compostos estudados 60

6 Conclusão 69

7 Referências Bibliográficas $\quad 70$

8 Anexos 73 


\section{Lista de Figuras}

Figura 1- Estrutura da Cisplatina $\quad 21$

Figura 2- Efeito da droga cis-diaminodicloroplatina(II) sobre a divisão da bactéria Escherichia coli 22

Figura 3 - Três possíveis espécies hidrolisadas de cisplatina 23

Figura 4 - Principais adutos formados na interação da cisplatina $\begin{array}{ll}\text { com o DNA } & 25\end{array}$

Figura 5 - Estrutura da penicilamina $\quad 28$

Figura 6 - Estrutura da glutationa 31

Figura 7 - Esquema da síntese biológica da glutationa 31

Figura 8 - Glutationa oxidada (GSSG) 32

Figura 9 - Interconversão entre GSH e GSSG 32

Figura 10- Esquema mostrando as interrelações das várias funções desempenhadas por GSH na homeostase celular 35

Figura 11 - Estrutura proposta para o composto

$\left[\mathrm{Pt}(\mathrm{Cl})_{2}(\mathrm{Pen})\left(\mathrm{NH}_{3}\right)_{2}\right] \cdot 2 \mathrm{H}_{2} \mathrm{O}$

Figura 12 - Estrutura proposta para o composto

$\left[\mathrm{Pt}(\mathrm{Cl})(\mathrm{GS})\left(\mathrm{NH}_{3}\right)_{2}\right] \cdot 2 \mathrm{H}_{2} \mathrm{O} \cdot \mathrm{HCl} \quad 46$

Figura 13 - Esqueleto estrutural do complexo

diaminodicloropenicilaminato platina (II) $\left[\mathrm{Pt}\left(\mathrm{NH}_{3}\right)_{2}(\mathrm{Cl})_{2}(\mathrm{Pen})\right] \quad 49$

Figura 14 - Esqueleto estrutural do complexo

diaminocloroglutationato platina (II) $\left[\mathrm{Pt}\left(\mathrm{NH}_{3}\right)_{2}(\mathrm{Cl})(\mathrm{GS})\right]$

Figura 15 - Curva termogravimétrica para a penicilamina 73

Figura 16 - Curva termogravimétrica para a glutationa 73

Figura 17 - Curva termogravimétrica para o composto de $\begin{array}{ll}\text { cisplatina e glutationa } & 74\end{array}$

Figura 18 - Curva termogravimétrica para o composto de cisplatina e penicilamina 
Figura 19 - Espectro de infravermelho para a cisplatina obtido com pastilha de $\mathrm{KBr}$

Figura 20 - Espectro de infravermelho para a cisplatina obtido com pastilha de polietileno

Figura 21 - Espectro de infravermelho para a glutationa obtido com pastilha de $\mathrm{KBr}$

Figura 22 - Espectro de infravermelho para a glutationa obtido com pastilha de polietileno

Figura 23 - Espectro de infravermelho para a penicilamina obtido com pastilha de $\mathrm{KBr}$

Figura 24 - Espectro de infravermelho para a penicilamina obtido com pastilha de polietileno

Figura 25 - Espectro de infravermelho para o composto de cisplatina e glutationa obtido com pastilha de $\mathrm{KBr}$

Figura 26 - Espectro de infravermelho para o composto de cisplatina e glutationa obtido com pastilha de polietileno

Figura 27 - Espectro de infravermelho para o composto de cisplatina e penicilamina obtido com pastilha de $\mathrm{KBr}$

Figura 28 - Espectro de infravermelho para o composto de cisplatina e penicilamina obtido com pastilha de polietileno

Figura 29 - Segunda derivada do espectro de infravermelho do composto de glutationa e cisplatina comparada com o espectro original

Figura 30- Segunda derivada do espectro de infravermelho do composto de glutationa e cisplatina comparada com o espectro original

Figura 31 - Segunda derivada do espectro de infravermelho do composto de glutationa e cisplatina comparada com o espectro original

Figura 32 - Segunda derivada do espectro de infravermelho do composto de glutationa e cisplatina comparada com o espectro original 
Figura 33 - Segunda derivada do espectro de infravermelho do composto de penicilamina e cisplatina comparada com o espectro original

Figura 34 - Segunda derivada do espectro de infravermelho do composto de penicilamina e cisplatina comparada com o espectro original

Figura 35 - Segunda derivada do espectro de infravermelho do composto de penicilamina e cisplatina comparada com o espectro original

Figura 36- Segunda derivada do espectro de infravermelho do composto de penicilamina e cisplatina comparada com o espectro original

Figura 37 - Espectro de deconvolução de bandas comparada com o espectro de infravermelho do composto entre cisplatina e glutationa Figura 38 - Espectro de deconvolução de bandas comparada com o espectro de infravermelho do composto entre cisplatina e glutationa

Figura 39 - Espectro de deconvolução de bandas comparada com o espectro de infravermelho do composto entre cisplatina e penicilamina

Figura 40 - Espectro de deconvolução de bandas comparada com o espectro de infravermelho do composto entre cisplatina e penicilamina

Figura 41 - Espectro de Raman para a cisplatina 97

Figura 42 - Espectro de Raman para a glutationa 98

Figura 43 - Espectro de Raman para a penicilamina 99

Figura 44 - Espectro de Raman para o composto entre cisplatina e glutationa

Figura 45 - Espectro de Raman para o composto entre cisplatina e penicilamina

Figura 46 - Espectro de infravermelho teórico para o composto entre cisplatina e glutationa

Figura 47 - Espectro de infravermelho teórico para o composto entre cisplatina e penicilamina 


\section{Lista de tabelas}

Tabela 1 - Dados de análise elementar

Tabela 2 - Fórmula empírica e massa molar para

os compostos sintetizados

42

Tabela 3 - Faixa de decomposição para os compostos sintetizados

Tabela 4 - Dados obtidos a partir da curva de decomposição

térmica dos compostos

Tabela 5 - Distâncias interatômicas calculadas para

o esqueleto estrutural do composto PtPen - $\left[\mathrm{Pt}\left(\mathrm{NH}_{3}\right)_{2}(\mathrm{Cl})(\mathrm{Pen})\right]-$

a partir do procedimento DFT:B3LYP/SDD comparadas

com valores obtidos por cristalografia de raios-X

Tabela 6 - Distâncias interatômicas calculadas para

o esqueleto estrutural do composto PtGlut - [Pt( $\left.\left.\mathrm{NH}_{3}\right)_{2}(\mathrm{Cl})(\mathrm{GS})\right]$ -

a partir do procedimento DFT:B3LYP/SDD comparadas

com valores obtidos por cristalografia de raios- $X$

Tabela 7- Ângulos de ligação calculados para

o esqueleto estrutural do PtPen - $\left[\mathrm{Pt}\left(\mathrm{NH}_{3}\right)_{2}(\mathrm{Cl})(\mathrm{Pen})\right]-$

a partir do procedimento DFT:B3LYP/SDD

Tabela 8 - Ângulos de ligação calculados para 0

esqueleto estrutural do PtGlut - $\left[\mathrm{Pt}\left(\mathrm{NH}_{3}\right)_{2}(\mathrm{Cl})(\mathrm{GS})\right]-$

a partir do procedimento DFT:B3LYP/SDD

Tabela 9 - Energias mínimas em Hartree e em Joule calculadas

para os compostos PtGlut e PtPen

Tabela 10 - Atribuição vibracional para os modos de estiramento $\mathrm{NH}_{3}$ do composto PtPen

Tabela 11 Atribuição vibracional para os modos de estiramento $\mathrm{NH}_{3}$ do composto PtGlut

Tabela 12 - Atribuição vibracional para os modos de estiramento $\mathrm{NH}_{3}{ }^{+}$do composto PtPen 
Tabela 13 - Atribuição vibracional para os modos de estiramento $\mathrm{NH}_{3}{ }^{+}$e $\mathrm{NH}_{\text {amida }}$ do composto PtGlut

Tabela 14 - Atribuição vibracional para os modos de estiramento $\mathrm{CH}_{3}$ e $\mathrm{CH}$ do composto PtPen

Tabela 15 - Atribuição vibracional para os modos de estiramento $\mathrm{CH}_{2}$ e $\mathrm{CH}$ do composto PtGlut

Tabela 16 - Atribuição vibracional para os modos de estiramento $\mathrm{C}=\mathrm{O}$ para os compostos PtGlut e PtPen

Tabela 17 - Atribuição vibracional para os modos de variações angulares $\mathrm{HCH}$ do PtGlut

Tabela 18 - Atribuição vibracional para os modos de estiramento PtN dos compostos PtGlut e PtPen

Tabela 19 - Atribuição vibracional para os modos de estiramento PtS e PtCl dos compostos PtGlut e PtPen 


\section{Lista de Símbolos}

GSH - Glutationa

IV - infravermelho

R - Raman

v - estiramento

$\delta$ - deformação

$\delta_{s}$ - deformação simétrica

$\delta_{d}$ - deformação degenerada

$\rho_{r}$ - oscilação pendular (rocking)

$\rho_{\mathrm{t}}$ - giro alternado (twisting)

$\rho_{w}$ - balanceio (wagg)

$\mathrm{s}$ - simétrico

as - assimétrico 
"Sim, todo amor é sagrado e o fruto do trabalho é mais que sagrado, meu amor. A massa que faz o pão vale a luz do seu suor. Lembra que o sono é sagrado e alimenta de horizontes o tempo acordado de viver."

Beto Guedes e Ronaldo Bastos, Amor de Índio 